\title{
C.I.R.C.U.I.T. Model - a strategic option in the pedagogical training of the constructivist teacher
}

\author{
Vali Ilie \\ Department for Teacher's Training, University of Craiova, Romania
}

Email address:

Brainstorming71@yahoo.com

\section{To cite this article:}

Vali Ilie. C.I.R.C.U.I.T. Model - a Strategic Option in the Pedagogical Training of the Constructivist Teacher. Science Journal of Education. Vol. 1, No. 5, 2013, pp. 68-76. doi: 10.11648/j.sjedu.20130105.14

\begin{abstract}
Interest in constructivist pedagogy gives rise to a series of research in education, especially in training future teachers. In this perspective, we have observed that the fundamentals of constructivism face teachers to certain background problems that have been generated by the paradigm changes and are, at the same time, connected to the need for constructivist and strategic models. The model that we have framed valorises specific principles and it is based on the construction of mental priority. In this chapter, we are showing the stages of a technological model that we developed within The Educational PTCT Project (The Initial Pedagogical Training of the Constructivist Teacher - 2008, 2009). The project was tested from 2010 to 2012, during the Curriculum Theory and Methodology course. We are emphasizing the fact that, in using it in practice, students can achieve very good results about their constructivist learning style. In the present study we are going to certify the efficiency of this model which we have named the C.I.R.C.U.I.T. Model. The results we have obtained with the experimental group give us the right to say that the model we have developed can bring a part in facilitating studying in the academic environment. The conclusion we came to is that constructivist teaching and learning represent a strategic option in forming future teachers, also creating the context of forming specific competence in teachers.
\end{abstract}

Keywords: Education, Teacher, Initial Training, Constructivism, Metacognition

\section{Introduction}

The constructivist paradigm of training represents an alternative to the traditional paradigm and it is an expression of postmodernism in education. A methodological solution to change paradigms proved to be the finding out and the usage of alternatives, approached under an actively integrated paradigm into the systems of educational reality $[1,2]$. The constructivist paradigm is used as a methodological solution in training teachers. As educational finalities are faced to paradigm change [3], we are interested in the extent to which constructivist pedagogy plays a part in accomplishing them.

As a theory of knowledge with interdisciplinary roots, constructivism stresses the mental stage, what happens inside the "black box" and underlies the following aspects: $[4,5,6]$ :

- It promotes the subjective, personalized knowledge and learning by processing and building its own data;

- The basis of learning is the cognitive or socio-cognitive conflict that has to be mentally solved;

- The interpretation of outer reality is made in accordance with its own experience, through reflexion;

- The important elements are the situations, the context, the group, the relations, the interactions and the cooperation;

- It stresses the organizational stage of the internal solving conditions of real, independent and group situations;

- It dominates the formative objectives - abilities, capacities, cognitive competence;

- It stresses the schemata construction, the mental models of understanding and solving;

- It refers to a series of projects that are themselves artefacts in a continuous process of construction, always perfectible and adaptable to the diversity of training situations that it anticipates;

- It valorises holistic, integrative learning, diversifying the roles of the learning individual.

We consider the metacognitive facility to be important in forming didactic competence in the future teacher-student by formulating questions. This is a model, a solution for the constructivist formation of scientific thinking, of knowing through research. As a matter of fact, the constructivist 
approach makes itself remarkable by the variety of models, methods and procedures of building knowledge, techniques and derived instruments [7]:

1. Strategies, models, methods that valorise the essence of constructivist learning: the model of empirical initiation in scientific knowledge (Laplane, 1997), the model of learning through research (Dettrick, 1998), the model of conceptual fields (Vincent, 1997) etc.;

2. Strategies, models, methods outlined on the stages of the building knowledge process: the model of the $5 \mathrm{E}$ (Bybee, 1999, 2001), the model of the epistemic plans (Collins \& Ferguson, 1993), the model of generative learning (Wittrock, 1990, 1992);

3. Strategies, models, methods that integrate in a constructivist way the inner conditions of learning: REAL model (Rich Environments for Active Learning) - Schott, 2001, the metacognitive facilitation through enunciating questions (White and Frederiksen, 1998);

4. Strategies, models, methods that explicitly valorise the outer conditions of learning: the situational knowing/learning model (anchored training, case study, the project method etc.), the collaboration and cooperation knowing/learning model (the mutual training model - Wilson \& Cole, 1991).

Desirable professionalization gives birth to a reconception of the initial training of teachers. "To professionalize" implies the idea of building and developing the necessary competence to unfold a profession, where it materializes through practical actions and specific criteria. The model of professionalizing a teaching career has at core the idea of competence: to demonstrate that a teacher is a professional, he/she will relate to essential criteria of evaluation (mastering pedagogical knowledge, using a complex of capacities and abilities, triggering skills and specific competence, developing attitudes, relating to certain values in projecting, organization, development and evaluation, in developing certain pedagogic contexts and solving different educational situations) $[8,9]$.

The model that we suggest relates to the goals and objectives of constructivist pedagogy and has it in mind to help students in self-directed learning, to correctly answer questions, formulate questions themselves and find the best answers in order to approach a problem and themes that are characteristic to the domain under study. By accessing this model, during their training as future teachers, students refer to metacognitive training that includes teaching as well as strategic learning [10].

Getting through the CIRCUIT model stages proves that understanding, being specifically personal mental and then group construction, is facilitated by previous experience, by direct exploration, by personal interpretation, by hypotheses and solution statements, by reflection on processes and procedures.

We have created this model so as to be applied during initial training, from the perspective of professionalizing teaching career in a constructivist style. That is why our goal is to check out the impact this model has on the efficient learning in students.

By learning in a constructivist manner, the future teachers will know how to teach the same way. This hypothesis brings into discussion the necessity of forming specific competence. It is not the volume of knowledge we acquire that is important but how we get to that scientific knowledge, by direct involvement and participation.

Getting rid of the knowledge transmitting habit, the constructivist teacher must think of teaching from the perspective of the central role the student has in knowing, by keeping an eye on the evolution of his/ her acquiring the competence of formulating questions, arguments and reflections.

The name of our model comes from the first letter of each stage it is meant to cover: C - contextualization, I interrogation, question, $\mathrm{R}$ - reaction, answer, $\mathrm{C}-$ conceptualization, $\mathrm{U}$ - utilization, $\mathrm{I}$ - interpretation and $\mathrm{T}$ testing. Being an instrument of constructivist strategy, it requires, from the teacher, good knowledge and understanding of the constructivist paradigm of instructing.

\section{Methodology and Methods}

This model points to traditional training, but it surpasses this perspective because of its explicit orientation towards construction. Thus, the aspects of construction are stressed (see stage 2), reference is made to previous experience as a basis for the resulted constructs (see stage 3), learning and searching is placed in a context, in different situations (see stage 1 and 5) and appeal is made to interpretation and reflection (see stage 6 and 7).

That is why we have tried, along our activity, to go beyond the classical training frame, inside which students also had the task to answer questions, but we offered them the opportunity to generate questions themselves; classical pedagogy also refers to symbols, but we have tried to transform them into instruments to build reality.

If traditional paradigm uses reflection, too, with us exercising it became obvious during the teacher - student dialogue, during group collaboration or during the debate of an aspect at the level of the whole working team.

Being built from the perspective of metacognitive training, our model contributes to a better mastering of knowledge, it influences the efficiency of solving tasks autonomously and it leads to reconsiderations of the personality by developing the motivation of learning and the affective control of assigning results.

Metaknowledge may be a result of constructivist activities that are accomplished by students: learning by discovering, formulating questions, solving problems, graphic processing of information etc.

The logical succession of stages and their content description contributes to the understanding of the specific features of the model.

An ensemble view on the model highlights the following stages (Table 1): Contextualization, Interrogation (Question), Reaction (Answer), Conceptualization, Utilization, Interpretation, Testing. 
Table 1. Global approach of the CIRCUIT model

\begin{tabular}{|c|c|}
\hline Stages/Steps & $\begin{array}{l}\text { Specific features } \\
\text { (Subject's involvement). Precautions }\end{array}$ \\
\hline Contextualization & $\begin{array}{l}\text { It refers to various informational materials. } \\
\text { Students may remain tributary to certain concepts } \\
\text { and information previously given }\end{array}$ \\
\hline $\begin{array}{l}\text { Interrogation, } \\
\text { Question }\end{array}$ & $\begin{array}{l}\text { It asks different questions. Teachers may impose a } \\
\text { certain list of questions }\end{array}$ \\
\hline Reaction, Answer & $\begin{array}{l}\text { It answers questions based on previous experience. } \\
\text { Students may postpone their answering questions }\end{array}$ \\
\hline Conceptualization & $\begin{array}{l}\text { They get into contact with support information; } \\
\text { identify the key aspects and concepts. The teacher } \\
\text { chooses the offering of information in final form } \\
\text { and not as a process }\end{array}$ \\
\hline Utilization & $\begin{array}{l}\text { They build their understanding and concepts } \\
\text { application in different situations. Difficulties may } \\
\text { appear due to culture and birth place }\end{array}$ \\
\hline Interpretation & $\begin{array}{l}\text { They enlarge their conceptual frame according to } \\
\text { interaction. Some might hide behind other people's } \\
\text { work }\end{array}$ \\
\hline Testing & $\begin{array}{l}\text { They evaluate and self-evaluate their answers, their } \\
\text { work and analyze errors. The identification of the } \\
\text { moment the error occurred may be avoided (which } \\
\text { is not recommended) }\end{array}$ \\
\hline
\end{tabular}

Along two academic years (2011-2012) we verified the efficiency of the CIRCUIT model on a sample of 156 students involved in the research: years I and II (The Faculty of Biology, The Faculty of Physics, The Faculty of Economic Sciences and The Faculty of Informatics). We must say that the students that were part of the research joined The Department for Teachers' Training and attend the Psycho-pedagogical and Methodological Training Module.

Table 2. Types of specializations of the students part of the project

\begin{tabular}{llr}
\hline Specializations & Total & \% \\
\hline Biology & 43 & $27,56 \%$ \\
Physics & 15 & $9,62 \%$ \\
Economics & 52 & $33,33 \%$ \\
Informatics & 46 & $29,49 \%$ \\
\hline
\end{tabular}

We had as a starting point the goals and objectives of cognitive-constructivist training: direct experience gain through contact, the understanding and primary processing of information, the formation of mental images that are necessary to understand, the use of abstract mental mechanisms in understanding, the use of the already known mechanisms and systems of mental organization etc.

\subsection{Contextualization (Step 1)}

Context individualizes the meaning of words; it facilitates the choice of a word among other words possible. The frame, the context, the situation mark out priorities for students in order to involve them in accomplishing goals, in reaching goals within the "learning episode". When we talk about the learning episode, we mean a distinguished learning event that is part of a larger, vaster happening or of a series of learning events.

In our work we started from the following presumptions about how students get themselves involved into real events, presumptions that are confirmed in practice [11]: students work individually and think about how to understand the learning event; students work in teams and think about how to share tasks in order to understand the learning event; students connect the previous knowledge and the experience they have acquired to the learning event; students ask and answer questions about the learning event; students share their thoughts and ideas about the learning event to the others; students reflect individually and inside the team they belong to during the learning event.

This first stage of the suggested model implies the teacher's intervention. If we approach the stage development from a classical perspective we will find out the teacher's activity prevails, offering by this the conceptual base and some support-information to the students. However, we can change the perspective by placing students in the middle of training.

However, we started from outlining the frame, the pedagogical context because, in constructivism, conceptualization takes place during the last phases of the process. Hence, students may be asked to write, for the start, these concepts on one page, on the condition that later they would cover the page entirely by drawing lines among concepts and explaining the connections. Students may benefit by the opportunity they have in relation to adding their own words on the map and to filling in the map with previously learnt concepts. Making the concept maps should always start with the goals. The concept map presented to the students is centred on the key-concepts of the topic, subject, problem brought into discussion.

We initially announced the subject of the course and we told students the objectives we were interested in, formulated from the perspective of cognitive-constructivist training. We have permanently related to the constructivist vision that approaches competence from a personal construction perspective: competence adapts to context.

\subsection{Question (Step 2)}

Formulating questions in learning a subject may help the understanding of its different aspects and may determine personal reflection, compelling to updating, to intra- and interdisciplinary correlations, to formulating hypotheses.

In specialized literature we find a large area of questions, rendering, this way, a dynamic character to didactic interrogation according to $[11,12,13]$ :

- the desired goal: restrictive or close, broad or open, stimulative or exploratory;

- the objectives of the cognitive domain: of information, knowledge, explanation, understanding, application, analyzation, synthetization, evaluation, valorization;

- the thinking processes: of classification, comparison, ordering, explanation, evaluation, counting;

- the difficulty level: low, medium or intermediary and high;

- the function: mnemotechnical, cognitive-reproductive and cognitive-productive; of checking memory and of 
stimulating thinking;

- the addressability: frontal, general or of assembly, direct, inverse, of relay and communication, of returning, imperative, of controvercy;

- the role fulfilled in the activity with the students: of guidance, leading, anticipation, clarification, integration;

- the framed goal: cognitive and affective, speculative, leading.

From the multitude of question types we have mentioned above, we will rest our attention on the cognitive and speculative questions as well as the medium and high level ones, as we have already verified their formative-constructive value. We consider that, from a constructivist perspective, they are more valuable as the intellectual collaboration offers optimum space to build a personal universe that has to be developed.

Cognitive questions have a constructivist value because:

a) Students remember data, task procedures, knowledge or values; they are part of the category that include enumerations, classifications, and definitions and are low difficulty level questions (eg. "How many stages are there ...?");

b) Students make simple deductions, usually resting on data given by the teacher, or questions of an intermediary level (e.g. "How does it compare to ...?");

c) Students formulate hypotheses, state causes and identify motifs that have not been used in that particular instructing unit; they are high level questions (e.g. "How can we explain...., element that cannot be found in the studied books?").

d) Students solve certain problems referring to the motivation of learning; they are high level questions (e.g. "Which are the steps for us to follow in solving this problem? Which is their right sequence?");

e) Students evaluate their own activity, the subject, the topic or the set of values; they are high level questions (e.g. "Have I done any mistake? How can I verify my answer?").

Speculative, affective and leading questions have a constructivist value because:

a) Students speculate or intuitively assume, find creative ideas and ask close or open questions (e.g. "What do you consider he will think if...?");

b) Students use empathy and feelings (e.g. "How do you think he will feel if...?");

c) The students that have understood the task and prove they can control the situation and draw the others attention may be stimulated to lead the activity on a certain sequence (ex. "Which group has solved the problem?", "Who needs help?").

Intermediary level questions require from students to describe the similarities and differences, to analyze, classify, synthetize, estimate. High level questions require from students to evaluate, verify, state causal relations, set conditions. Students can suggest alternatives, can make predictions, a plan, can solve conflicts, transform or generalize the results they have reached.

There are a few particularities of building questions which we had in mind in developing didactic activities with a constructivist character:

- the variety and proportion, the nature and succession of questions depend on the content of the topic, previous experience, help in formulating them;

- a clearer formulation is made obvious during independent work in contrast with direct conversation with the teacher, when contact with the text and personal thinking time are favourable;

- $\quad$ if with younger students, information, identification and causal questions prevail, with older students the proportion of explaining, anticipating and systematizing questions increases;

- the value of the questions vary according to the relation between the text (its formulation) and the context of information it is framed in (eg. The question "why?" may turn into a memorizing question the moment it corresponds exactly to some explanations in the manual/ course, which the pupil/ student only reproduces);

- the constructivist questions are facilitated by the way teaching is organized, by the essentialized presentation of the content, by the appeal to identifying key-words, by affirming personalization in learning.

During this stage not all questions must be very well directed as the students might ask questions about anything, event, situation, problem, phenomenon that might be connected to the topic or the subject of the course. In order to go beyond the traditional frame, we have concentrated on formulating cognitive, speculative, affective, leading, medium, intermediary and high level questions.

\subsection{The Answer (Step 3)}

By using their own experience, students build the meaning of the new information they receive. This intention is, in fact, the core of constructivism because it strengthens the connection between old and new knowledge.

The important thing is the way stored information inflects with the new information, the first being the code for the second. The scarcity of previous knowledge is a handicap for understanding; it makes it be superficial, fragmentary and even false.

Few students are aware of their own difficulties in learning as they have no strategy of approaching them. The teacher should implicitly and explicitly encourage students to answer questions.

The process is not easy; sometimes, answering simple questions implies a minimum of knowledge or understanding. It is important to make students ask questions themselves and also encourage them to be efficient along the process: "Good question! Very interesting!", "Your question proves you are thinking of a lot!"

The teacher may encourage students ask questions that 
can highlight the difficulty of the task: "I haven't thought of this question, aspect of the problem!", "It seems there are many of us confused so that your question came right on time!".

If students start to impute their difficulty to answer to their own lacks, the teacher is expected to guide their attention towards outer difficulties: "This is a new kind of problem. We haven't discussed it yet so don't expect to know how to solve it!", "Don't expect your mind will work very fast. It requires some time!". It is important that we concentrate on the outer circumstances when students cannot give the expected answers to certain questions or make it clear that it can happen to all of us, to be asked questions that we cannot answer: "We can all have our difficult moments!".

A constant concern was that of encouraging students to ask questions and try to answer them using their previous experience. Not all students answered the questions, particularly the more difficult ones that required their ability to analyze, synthesize, evaluate and set causal relations. Only few answered high level speculative, leading questions.

We consider that future teachers will be able to access the way of scientifically knowing in their activity with students by learning it, individually and in groups, actively and not by being transmitted to them by understanding.

\subsection{Conceptualization (Step 4)}

During this stage, questions and answers are clearly centred on the topic of the course, on the key-concept, which is in the middle of the concept map. This time, the situation must be considered a challenge for students, something that will raise their interest and actively introduce them into understanding the task as a whole, so that they could fulfill it.

The characteristics of the cognitive structure play a special part: complexity (the extension degree, the scarcity or richness of the cognitive structure, its organizational degree, the articulation or disarticulation of its components), efficiency (the flexibility and mobility degree), finality (the quality of the effect is dependent on the quality of the cognitive structure, on the significance the subject gives to information as well as to processes), the evolutive character (evolution may be progressive or regressive).

The concept is an intellectual instrument which gives us the possibility to sense relations already existent among certain phenomena. They cannot fall apart judgement and reasoning because, every time we try a definition of a concept, we send to other concepts they are subordinated, coordinated and superordinated to.

We have already stated which are the key-concepts and phrases and we have advised students to put them down on a piece of paper so that they can later make connections, enrich or enlarge this list. We have encouraged students to enumerate different words connected with the topic, admitting empirical concepts that are most often enscribed into an inductive logic.

Being aware of the fact that concrete and particular features, restrictive attributes, accidental and unessential dependencies persist in empirical concepts we considered they can be a first step to understanding the subject. The scientific notions refer to the essential characteristics of objects and phenomena, their objective significance coming into their content. In an environment abundant in technology the teacher's role is that of a facilitator, who prepares the social and intellectual environment that favours participative and collaborative learning.

After the students divided themselves into three groups according to preference and affinity we gave them tasks to solve as creatively as they can and refer, while solving, to the constructivist paradigm of learning.

\subsection{Utilization (Step 5)}

We consider the utilization of mental mechanisms to be important in the understanding: of integration, of categorizing, of conceptualization, of making judgements and inferences, of solving problems, of conflictual situations, of making decisions.

Students exteriorize all their thoughts, ideas that come out during the solving process of the didactic tasks, the solving of the problems and during accomplishing the other mental mechanisms. The teacher should follow how accurate the ideas, the errors and contradictions of the students' activity are, offer clear instructions about how tasks and problems should be treated. Understanding concepts is not enough; they must be used in different contexts making sure that we master the multitude of existent connotations. It is considered that acknowledging the needs of the students and focusing on their presence in the course room are ways of finding and producing solutions to the problem of motivation [14].

The selection and assimilation as well as the settlement of outer influences come up at the same time with the motivational structures of the individual. The right answers rest on understanding the ideas; that is why, courses must be thought out so as the students can understand them. Being a form of thinking, understanding might be guided by certain intentions or points of view. Dependent on the degree of difficulty (the distance between old and new knowledge), understanding comes fast, simply, spontaneously or during a long, multiphasic, developed and discursive process.

This application and utilization process of concepts in various situations, their multiple perspective approach offers the guarantee of thorough learning. The contingence of interactions may lead to differences among students. Interpersonal intelligence that alludes to other people's capacity to understand and to the correct translation of their expectations and beliefs is the important thing because culture, which has strong affective resonance, may be approached as a certain way of perceiving, believing and evaluating.

In constructivist training we took into account variables as: rhythm of learning, time at hand, time needed by the subject to solve the task or answer the question, the kind of identified educational needs, the punctual moment in the 
subject's evolution, the availability of the used methods etc. This stage, as well as the following, allows the valorization of differences.

The teacher establishes a balance between individual and group norms, respecting the instructional level of each student, offering the chance to search, express oneself, tell his own point of view to the others, personal approach, variant, process to everyone. Using their own formal and informal experience, students were able to assert their creativity and cognitive flexibility.

In finding possible aspects, in selecting problems, sources, in combining points of view we referred to a series of methods, procedures, techniques, instruments which were approached from a constructivist perspective.

The exercise is part of the training techniques category but it should not be understood as a mechanical repetition, a repeated impression of actions but as an intensive and extensive reusing of some significant elements and structures that correspond to the learning tasks in contexts and real life situations. Among the used exercises there are: "Improvised presentations" exercise, "My face" exercise, role play, the conversation method, solving problems.

\subsection{Interpretation (Step 6)}

A permanent concern for the teacher should be to identify ways to make students not only read but also understand because when students read a scientific text, they try to learn the key-words and understand the main ideas so that they could give back information, but are no longer capable to do so. In other words, some students try to understand and put together beliefs and information from the text they read. Sometimes, students need help to focus on major concepts; they often forget to identify and understand important concepts.

Students activate previous knowledge and recognize situations when they are similar to the ones in the text. Students solve discrepancies by redefining their ideas; they use strategies that exhibit personal norms which represent the essence of independent learning. We should not omit the formative contribution of self-directed questions that students can formulate answers for, answers that are able to clear the concepts they had in mind: "Is this so unclear to me?", "What should I do to clarify my understanding?".

The teacher should suggest students to think about the situations when they discover contradictions between what they read in a book and what they already know. Discussing the strategy they use while reading should make ideas clear during reading the text. Starting from the texts read during the unit or sequence of learning, there can be formed representations and notions.

Representations, as figurative symbols, have a presentation function that is necessary for elaborating notions. Representations, as support in establishing the meaning of words, precede the logical control of the correctness of the thinking process.

Even if, at first, the words from the texts do not say anything, in time, by stressing the interpretation of texts, they can get to a stage of crystallizability and fixation of meanings. Working in groups, students have the possibility to cooperate in solving tasks, each of them bringing his contribution to enriching and filling in the concept map, by understanding the notions.

Referring to learning through cooperation, students made exchanges, confrontations, ideas interferations and negotiated in choosing the most suggestive situations and examples. They considered that this modality represented an exciting thing as they were given the possibility to reason, express their ideas and, at last, activate themselves and be active in building knowledge.

Reflexion has a very important role. Students critically examined their own performance and difficulties in knowing and solving tasks. Subsequent personal reflexion allowed a comparison of the understanding and solving modalities they received with the given criteria, the others' accomplishments and personal previous stage. In the first part of the reflexion we engaged the entire group in interpreting and finding the meaning; in the second stage the students reflected on what they learnt during the approaching of the task and the presentation of solutions.

Reflexion includes what students remembered about their ideas, feelings, images and process during the internal dialogue. Students individually identified which ideas of theirs appeared in the learning unit, registered their ideas and saw them again later, reanalyzed them from several perspectives.

We consider personal reflexion to be important, too; that is why we concentrated on answering questions like:

- "How can I guide students in group work, in collaborating with each other?"

- "What attitudes will they have, what concepts will they take with them?"

- "What will students remember about the feelings, images and language used in this learning unit/training event?" etc.

We drew attention on the need of formulating such questions by the future teachers, too, who should know that they partially contribute to building a career. At the same time, we led collective observations along the learning unit; we gathered data on individual understanding of students and identified missing concepts. Students themselves turned during this stage to self-directed questions that reflect not only knowledge but also procedures, attitudes and interests.

\subsection{Testing (Step 7)}

During this stage intra- and interdisciplinary connections are evaluated, uncertain questions are answered, the final answer is given, and errors made by the students are analyzed all along the learning process. Starting from the major goal of the research that intends to train the constructivist teacher, in evaluation we were more interested in the elements that led to building knowledge (capacities, abilities, understanding and individual construction competence, acquired learning experience, proved attitudes etc.). 
Resting on what students read and talked about, they had the possibility to prove this competence. By filling in the concept map, initially suggested by the teacher, we could see progress on stages. The teacher can also act differently: draw an incomplete concept map and only give a few complementary elements.

From the options offered by each stage of the Circuit Model there comes its openness to construction: of the teacher and of the students. Learning how to work with alternatives the future constructivist teacher will know to offer his students various opportunities of learning that will require permanent construction.

The constructivist teacher understands evaluation as a communication process between him and the pupils which uses information on the quality of learning. The attitudes of valorizing ideas, interpretations, reflections are important at the same extent as the critical analyze of errors in self-evaluation.

When students realize they gave the wrong answer to a question or did not solve the didactic task correctly they are recommended to analyze errors: "What did I answer wrongly?", "What element, aspect of the didactic task prevented me from solving it correctly or identify the right solution?"; "Why didn't I choose the right answer?", "Why didn't I solve the didactic task correctly?"; "How could I remember, how could I find out which the right answer is?", "How will I solve the didactic task correctly?"

We have tried to avoid mistakes that the teacher usually does when asking questions and require questions from the students [15]:

a) Distribution: formulates unclear questions, speaks too slowly or too fast, too loud or too low, does not make visual contact with the students while asking the question;

b) Structuring: uses an unclear vocabulary, too long and complex questions that require too much time to answer, does not formulate clear requests;

c) Establishing the goal: does not direct the question, define or make it clear to whom is the question addressed (to one student? A group of students? To all the students?;

d) Setting the conditions: does not place the question into a defined frame or context connected to the topic of the course;

e) Waiting for the answer: does not give the right to answer a question, gives too little time for the students to answer, stops only at the answer he is waiting for;

f) Ensuring discipline and management: does not allow students to give more or other answers at the same time;

g) Levelling: asks questions that are too hard or too easy to reach the goal.

The post-evaluation stage ends the learning construction stage and opens to other contents. We can use methods like: possible applications of the new concepts, portfolio filling in, making reports on the whole construction, systemize information in diagrams or tables etc.
Testing is the last stage of the model suggested and it has in the middle increasing attention, filling in the conceptmap and errors analyzing. Even if I have not insisted on presenting my personal reflexion results publicly it can be a way of practising group communication and relational competence verification.

\section{Results}

We have observed that the tendency to stress qualitative aspects in evaluation becomes a necessity without getting apart from the quantitative evaluation of the extent of knowledge and abilities.

We have stressed mechanisms, stages, determinant factors and learning processes evaluation, most of all. Extended to processes, evaluation gave us essential feed-back suggesting adopting adequate measures.

The research method we consider to be important in our work is the experiment. The experimental pattern we turned to (with a pre-test and a post-test) assumes a design with two equivalent groups. By using classical training, we have observed that students do not reach the formative and educational goals aimed at (at least 50\%) in a satisfactory way. The low results of the pre-test (found in the following table) show the unsatisfactory results of the students, related to the items set as marks.

Starting from this observation, we have implemented the C.I.R.C.U.I.T. Model and applied it on the experimental group (made of 78 students from the University of Craiova, at the already mentioned faculties). With the other 78 students (from the same faculties) - organized into a control group - we worked in the traditional manner, while the independent variable (the Circuit Model) was used only in working with the students in the experimental group. As there was no considerable difference between the scores obtained in the pre-test by the two groups, we considered them to be equivalent. For the experimental group we appealed to our model and stressed the elements characteristic to the constructivist training.

We needed to see if there are quantitative differences, mainly qualitative ones, in getting the final results (at the end of the second academic year), for the taught subject (Curriculum Theory and Methodology).

Table 3. Types of specializations of the students part of the research

\begin{tabular}{lllll|l}
\hline $\begin{array}{l}\text { The stages } \\
\text { of the } \\
\text { CIRCUIT } \\
\text { Model }\end{array}$ & Items & $\begin{array}{c}\text { The Control } \\
\text { Group }\end{array}$ & \multicolumn{2}{l}{$\begin{array}{l}\text { The } \\
\text { Experimental } \\
\text { Group }\end{array}$} \\
& & $\begin{array}{l}\text { Pre- } \\
\text { test }\end{array}$ & $\begin{array}{l}\text { Post- } \\
\text { test }\end{array}$ & $\begin{array}{l}\text { Pre- } \\
\text { test }\end{array}$ & $\begin{array}{l}\text { Post- } \\
\text { test }\end{array}$ \\
\hline & $\begin{array}{l}\text { 1. Understand- } \\
\text { ing the theme }\end{array}$ & $45 \%$ & $57 \%$ & $42 \%$ & $65 \%$ \\
\hline $\begin{array}{l}\text { 2. Using } \\
\text { alization }\end{array}$ & $\begin{array}{l}\text { bibliographical } \\
\text { marks }\end{array}$ & $24 \%$ & $35 \%$ & $31 \%$ & $58 \%$ \\
\hline & $\begin{array}{l}\text { 3. Right } \\
\text { decoding of the }\end{array}$ & $38 \%$ & $48 \%$ & $34 \%$ & $74 \%$ \\
\hline
\end{tabular}




\begin{tabular}{|c|c|c|c|c|c|}
\hline \multirow{2}{*}{$\begin{array}{l}\text { The stages } \\
\text { of the } \\
\text { CIRCUIT } \\
\text { Model }\end{array}$} & \multirow[t]{2}{*}{ Items } & \multicolumn{2}{|c|}{$\begin{array}{c}\text { The Control } \\
\text { Group }\end{array}$} & \multicolumn{2}{|c|}{$\begin{array}{l}\text { The } \\
\text { Experimental } \\
\text { Group }\end{array}$} \\
\hline & & $\begin{array}{l}\text { Pre- } \\
\text { test }\end{array}$ & $\begin{array}{l}\text { Post- } \\
\text { test }\end{array}$ & $\begin{array}{l}\text { Pre- } \\
\text { test }\end{array}$ & $\begin{array}{l}\text { Post- } \\
\text { test }\end{array}$ \\
\hline & concept map & & & & \\
\hline \multirow{2}{*}{$\begin{array}{l}\text { Interroga- } \\
\text { tion }\end{array}$} & $\begin{array}{l}\text { 4. Finishing the } \\
\text { questions list }\end{array}$ & $17 \%$ & $39 \%$ & $20 \%$ & $59 \%$ \\
\hline & $\begin{array}{l}\text { 5. Active } \\
\text { listening }\end{array}$ & $29 \%$ & $45 \%$ & $32 \%$ & $68 \%$ \\
\hline \multirow{3}{*}{ Reaction } & $\begin{array}{l}\text { 6. Appealing to } \\
\text { previous } \\
\text { experience }\end{array}$ & $43 \%$ & $63 \%$ & $40 \%$ & $86 \%$ \\
\hline & $\begin{array}{l}\text { 7. Giving right } \\
\text { answers }\end{array}$ & $26 \%$ & $60 \%$ & $24 \%$ & $82 \%$ \\
\hline & $\begin{array}{l}\text { 8. Giving full } \\
\text { answers }\end{array}$ & $37 \%$ & $54 \%$ & $32 \%$ & $89 \%$ \\
\hline \multirow{2}{*}{$\begin{array}{l}\text { Conceptu- } \\
\text { alization }\end{array}$} & $\begin{array}{l}\text { 9. Finding } \\
\text { anchor-ideas }\end{array}$ & $25 \%$ & $57 \%$ & $31 \%$ & $93 \%$ \\
\hline & $\begin{array}{l}\text { 10. Delimitting } \\
\text { key- concepts } \\
\text { from details }\end{array}$ & $47 \%$ & $75 \%$ & $43 \%$ & $90 \%$ \\
\hline \multirow[b]{2}{*}{ Utilization } & $\begin{array}{l}\text { 11. Improving } \\
\text { context }\end{array}$ & $26 \%$ & $56 \%$ & $28 \%$ & $75 \%$ \\
\hline & $\begin{array}{l}\text { 12. Applying } \\
\text { concepts in new } \\
\text { situations }\end{array}$ & $12 \%$ & $46 \%$ & $16 \%$ & $65 \%$ \\
\hline \multirow{3}{*}{$\begin{array}{l}\text { Interpreta- } \\
\text { tion }\end{array}$} & $\begin{array}{l}\text { 13. Capacity of } \\
\text { reflection }\end{array}$ & $15 \%$ & $30 \%$ & $22 \%$ & $78 \%$ \\
\hline & $\begin{array}{l}\text { 14. Reasoning } \\
\text { view points }\end{array}$ & $34 \%$ & $64 \%$ & $31 \%$ & $97 \%$ \\
\hline & $\begin{array}{l}\text { 15. Getting } \\
\text { involved in } \\
\text { solving group } \\
\text { tasks }\end{array}$ & $27 \%$ & $51 \%$ & $28 \%$ & $86 \%$ \\
\hline \multirow{2}{*}{ Testing } & $\begin{array}{l}\text { 16. Improving } \\
\text { concept maps }\end{array}$ & $46 \%$ & $76 \%$ & $50 \%$ & $95 \%$ \\
\hline & $\begin{array}{l}\text { 17. Self-evalua- } \\
\text { tion capacity }\end{array}$ & $38 \%$ & $65 \%$ & $35 \%$ & $81 \%$ \\
\hline
\end{tabular}

We are showing below the results obtained by the two groups in the post-test (group $1-$ control and group $2-$ experimental).

Table 4. The items for which the students in the experimental group got higher scores in the post-test related to the witness group

\begin{tabular}{ccc}
\hline Itemi & $\begin{array}{c}\text { Grupa 1 } \\
\text { (The Control Group) }\end{array}$ & $\begin{array}{c}\text { Grupa 2 } \\
\text { (Experimental Group) }\end{array}$ \\
\hline Item 8 & $54 \%$ & $89 \%$ \\
Item 9 & $57 \%$ & $93 \%$ \\
Item 13 & $30 \%$ & $78 \%$ \\
Item 14 & $64 \%$ & $97 \%$ \\
Item 15 & $51 \%$ & $86 \%$ \\
\hline
\end{tabular}

Students filled in the concept map they started from initially by working independently-individually. Each student built his own knowledge and learning by using previous and direct experience in finding the meaning of the new information and in filling in the concept map.
In evaluation we have looked for the way of building solutions, searching abilities, establishing relations, through pedagogical feed-back.

We were also interested in the self-evaluating reflection which proved its value along the process of analyzing registered errors.

\section{Discussion}

In the criterial analyzis of progress, of the way to understand and work with information students came into contact with, they tried to find the difficulties that led to error appearance. Thus, they asked questions like: "What did I do wrong in interpreting the suggested text?", "Why did the others consider my point of view to be pointless?", "What could I do to write down all the anchor ideas?" etc.

The evaluation criteria are important, too: "In most cases teachers are not able to invoke explicit standards to appreciate which connections, which integrations, which syntheses are valid and how are (or are not) they meritory. In order to judge a project, criteria extracted from the proper domain must be invoked (...) as well as criteria that are concordant with the subject/ subjects of the project (...)" [16].

By understanding the usefulness of this model, we can state that we have succeeded to combine a series of instruments, materials, acting models, information, criteria and tasks. We have turned to procedures considered to be insufficiently studied and used:

- Procedures of confronting yourself: out loud thinking, inner monologue, verifying personal understanding during the process of knowing;

- Verifying by paraphrasing, personal reflection, reflection and discovery of the learning style;

- Active procedures: solution verification, similar situation application, problem solving, computer learning, graphical processing of information;

- Interactive procedures: pair or team learning, training by role change;

- Self-esteem, self-encouraging, anxiety reduction, personal success stressing, self-trust assertion procedures.

Metacognitive facilitation through formulating questions represented, for our model, a solution to forming scientific thinking in a constructivist manner and to knowing by research. We considered it important not to inhibit the students' personal constructions but postpone evaluation until finding arguments by each student or group.

After the final results, we have observed that the students taking part in this pedagogical experiment (the ones in the experimental group) reached the objectives set for the final test in a bigger percentage than the students in the control group. It is also true that the students in the witness group got better performance at the end of the training programme, but worse than those of the students for whom we introduced the independent variable.

This fact emphasizes the efficiency of the CIRCUIT 
Model and entitles us to say that the model we have created and tested in practice can represent a successful strategic variant.

Referring to comparative analysis, we have observed higher scores in the specific items of the penult stage (Interpretation), which highlights the influence of applying the model on developing the students' capacity of reflexion but also the possibility of stimulating the involvement in solving group tasks through it.

The capacity of reasoning own ideas, points of view bettered and, thus, we can assert that, according to facts, students from the experimental group identify faster and more easily the anchor-ideas and give full answers.

\section{Conclusions}

As a conclusion, the C.I.R.C.UI.T. Model shows that learning through constructivist understanding does not depend exclusively on the teacher as a transmitter, but derives from independent searching and also from interactive learning (with the others, with the computer etc.). The knowledge society is one of complexity, integrativity, reflexivity and interpretation.

Forming competence in the constructivist teacher requires the use of a constructivist methodology while the model suggested represents a working instrument that combines classical elements with strictly constructivist ones, surpassing the traditional ones and opening various perspectives towards knowledge and learning.

In the context of the presented hypothesis, training a teacher in a constructivist manner can answer to the new social requirements-expectations. We are optimistic that the constructivist paradigm can prove the professional level exactly because it directly entrains future teacher - students in their own initial training.

The "CIRCUIT Model" is a strategic training version where we stressed the construction aspects, getting the future teacher-student ready to work in a constructivist manner as a sign of professionalization.

\section{References}

[1] Mackenzie, Noella and Knipe, Sally, Research dilemmas: Paradigms, methods and methodology Issues In Educational Research 16 (2), 2006, pp. 193-205, http://www.iier.org.au/iier16/mackenzie.html

[2] Demers, Pierre, $\square$ lever la conscience humaine par $l \square e ́ d u c a t i o n$. Essai, Presse de $1 \square$ Université du Quebec, 2008, pp. 51-52, In http://www.books.google.com/books?isbn?=2760515540

[3] Rey, Bernard; Carette, Vincent; Defrance Anne and Kahn
Sabine, Les compétences à $l \square e ́ c o l e$. Apprentissage et évaluation, 2006, pp. 22-23. In http://www.books.google.com/books?isbn=2804142795.

[4] Duffy, M. Thomas and Cunningham, J. Donald, Constructivism: Implications for the design and delivery of instruction, 1996, pp. 5-20. In http://www.newmedia.nenu.edu.cn/wyn

[5] Doise, Willem; Mugny Gabriel and Pérez, A. Juan, The social construction of Knowledge: social marking and socio-cognitive conflict. In The Psychology of the Social, Edited by Uwe Flick, Chambridge Universty Press, 1998, pp. $77-91$

[6] Jonassen, H. David, Designing Constructivist Learning Environments. In Instructional-Design Theories and Models. A New Paradigm of Instructional Theory. Vol. II, Edited by Charles M. Reigeluth, New York, 1999, pp. 215-223

[7] Joița, Elena, Constructivist training - an alternative. Fundamentals. Strategies, Bucharest: Aramis Publishing House, 2006, pp. 138-192

[8] Korthagen, A. J. Fred, In search of the essence of a good teacher: towards a more holistic approach in teacher education, 2003, pp. 88-93. In http://www.igitur-archive.library.uu.nl/ivlos/2008-0805-201 418/korthagen $\% 20-\% 20$ in $\% 20$ search $\% 20$ of $\% 20$ the $\% 20$ esse nce.pdf

[9] OECD, The Definition and Selection of Key Competences. Executive summary, 2005, pp. 5-19. In http://www.oecd.org/pisa/35070367.pdf

[10] Vrugt, Anneke and Oort, Frans, Metacognition, achievement goals, study strategies and academic achievement: pathways to achievement, 2008, pp. 126-130. In Metacognition Learning,

http://download.springer.com/static/pdf/576/art\%253A10.10 07\%252Fs11409-008-9022-4.pdf?auth66=1383550146_152 cd34f41b87flbfa179d30da0dd0e8\&ext=.pdf

[11] Gagnon W. George and Collay, Michelle, Design for Learning. Six Elements in Constructivist Classrooms, California: Corwin Press, 2001, p. 6

[12] Cerghit, Ioan, Teaching methods, Bucharest: EDP R.A., 1997, pp. 119-120.

[13] Hartman J. Hope and Glasgow A. Neal, Tips for the Science Teacher. Research-Based Strategies to Hetp Students Learn, California: Corwin Press, 2002, pp. 47-48.

[14] Henson Kenneth T., Constructivist Teaching Strategies FOR DIVERSE MIDDLE-LEVEL CLASSROOMS, Boston: Allyn and Bacon, 2004, p. 325.

[15] Brown G. A. and Edmondson R., Asking questions. In Classroom teaching skills, Edward Conrad Wragg, Ed. New York: Nichols, 1989, pp. 97-120.

[16] Gardner Howard, Five minds for the future, Bucharest: Sigma Publishing House, 2007, pp. 107-108. 